\title{
Papers
}

\section{Correlation between apoptosis macroarray gene expression profiling and histopathological lymph node lesions}

\author{
J P Dales, J Plumas, F Palmerini, E Devilard, T Defrance, A Lajmanovich, V Pradel,
} F Birg, L Xerri

\section{INSERM U 119, Institut Paoli-Calmettes, IFR 57 and Université de la Méditerranée, 13000 \\ Marseille, France \\ J P Dales \\ F Palmerini \\ E Devilard \\ F Birg \\ L Xerri}

Immunology

Department, ETS

Isère-Savoie, and

Research Group on

Lymphomas, Unité

UPRES 2021, 38000

Grenoble, France

J Plumas

A Lajmanovich

INSERM U 404, 65000

Lyon, France

T Defrance

Biostatistics

Department, Hôpital

Sainte-Marguerite,

13000 Marseille,

France

V Pradel

Correspondence to: Dr Xerri, Department of Pathology, Institut

Paoli-Calmettes, 232

Boulevard de Sainte

Marguerite, BP 156, 13273

Marseille Cedex 9, France

xerril@marseille.fnclcc.fr

Accepted for publication 26 October 2000

\begin{abstract}
Aims-Microarray technology has recently led to the identification of molecular prognostic subgroups in nonHodgkin's lymphomas. To determine the usefulness of ready made macroarrays as routine diagnostic tools in haematopathology, lymph node biopsies were analysed using a cDNA macroarray containing genes involved in apoptosis, including caspases.
\end{abstract}

Methods-Nine biopsy specimens were analysed using total frozen tissues: four samples of B cell follicular lymphoma, two of $B$ cell diffuse large cell lymphoma, and three of non-neoplastic lymph nodes from benign lymphadenitis. Nine cell populations were sorted from fresh tissues: malignant $B$ cells from two patients with follicular lymphoma and two with diffuse large cell lymphoma, reactive $B$ cells from two benign lymph nodes, reactive $T$ cells from one benign lymph node, and virgin (mantle zone) $\mathbf{B}$ cells and germinal centre $B$ cells from benign tonsils. Immunohistochemistry (IHC) on paraffin wax sections was performed for the localisation of caspases 2, 3, 4, 7, 8, and 9 .

Results-In the clustered array data, sorted cells from samples sharing common histological lesions were grouped together, whereas the array/histology correlation was less satisfactory for tissues. The expression profiles of both the array and IHC methods correlated for most caspases and samples.

Conclusions-Variations in array profiles of sorted cell populations can be associated with specific histological features, suggesting a possible diagnostic application of ready made apoptosis macroarrays in haematopathology.

(f Clin Pathol: Mol Pathol 2001;54:17-23)

Keywords: macroarrays; apoptosis; gene profiling; nonHodgkin's lymphomas; caspases; immunohistochemistry

Microarrays in which polymerase chain reaction (PCR) products from cDNAs are ar- ranged on nylon membranes and hybridised to radioactive probes are an attractive new approach for large scale gene expression analysis. ${ }^{1}$ This method allows the simultaneous, quantitative measurement of the expression of many genes, and can detect genes that are differentially expressed in different cell lines or tissues. $^{2-4} \mathrm{~A}$ recent microarray study based on almost $18000 \mathrm{cDNA}$ clones has led to the identification of molecular subgroups of nonHodgkin's lymphomas with distinct prognostic relevance. ${ }^{5}$ Thus, studies to aid the transition of microarray technology into routine use are necessary.

Ready made macroarrays produced by several manufacturers might be an alternative possibility for routine pathology practice. Specific panels of genes are available. Among these panels, apoptosis regulating genes are attractive for haematopathologists, because nonHodgkin's lymphomas are known to display some abnormalities in the cell death process, such as the overexpression of BCL-2, which has prognostic value in some non-Hodgkin's lymphoma types, ${ }^{6}$ or resistance to FAS mediated apoptosis. ${ }^{7-9}$ We have assumed that the expression of apoptosis regulators can be correlated with the diversity of histopathological lymph node lesions. To check this hypothesis, we have analysed lymph node biopsies using a ready made cDNA array containing genes involved in cell death, including caspases, which are considered to be crucial cell death effectors. ${ }^{10}$ Immunolocalisation of some caspases in lymphoid tissues has been already described, ${ }^{11}{ }^{12}$ so we intended to investigate the correlation between immunohistochemistry (IHC) and array data.

Our data show that specific variations in array profiles can be associated with different histological features, thereby suggesting a possible diagnostic application of ready made macroarrays in lymph node pathology.

\section{Materials and methods}

TISSUE SAMPLING

Surgically removed lymph nodes were obtained from different, untreated patients. NonHodgkin's lymphomas were typed according to the REAL/OMS classification. ${ }^{13}{ }^{14}$ A portion of 

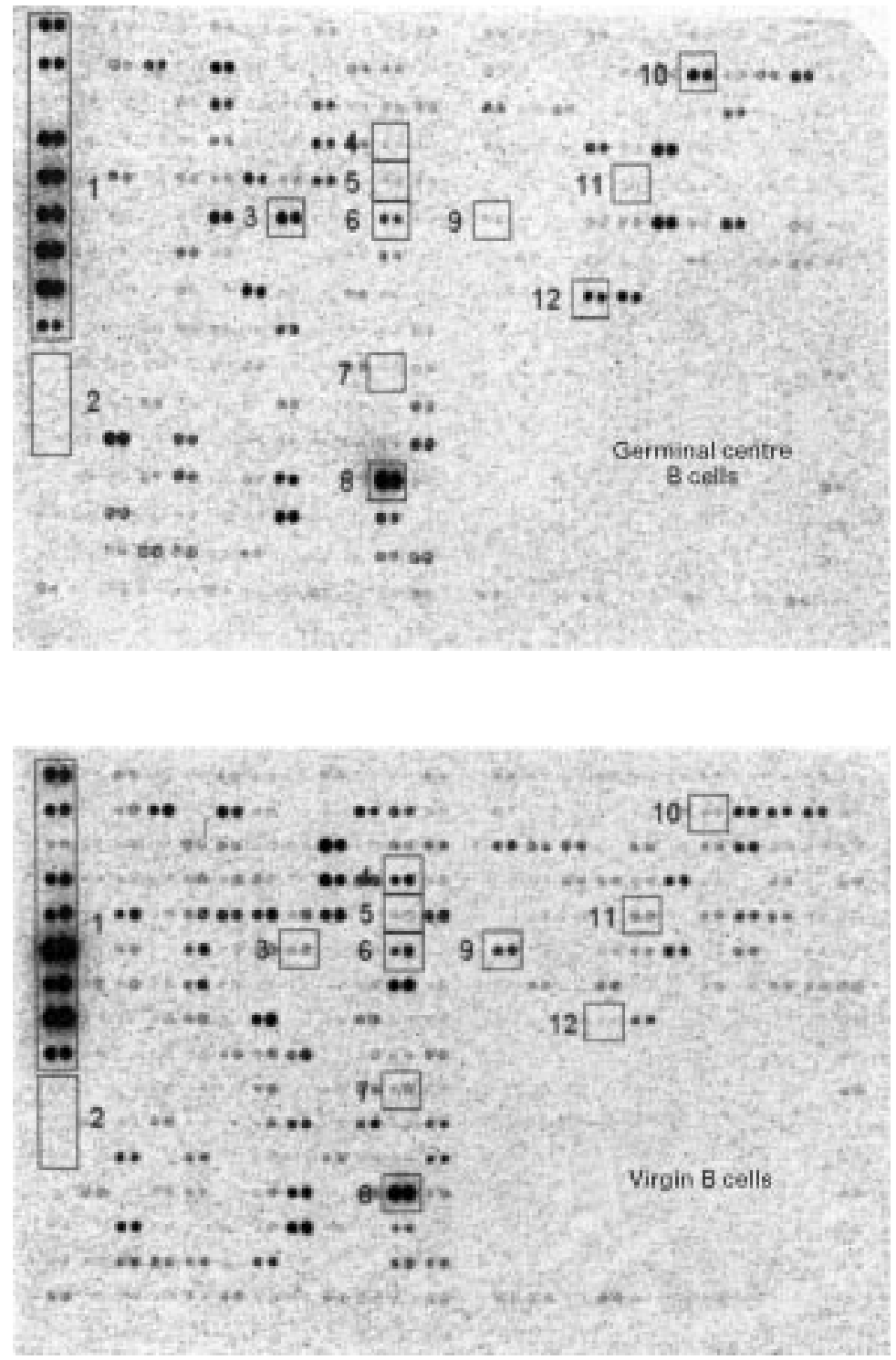

Figure 1 Gene expression profiles of two purified B cell samples. Membranes were hybridised with complex probes prepared from germinal centre $B$ cells (top) and virgin $B$ cells (bottom). Each membrane contains duplicate spots of cDNA fragments of 217 genes implicated in cell death and cell cycle regulation. Selected hybridisation signals refer to controls or examples of differentially expressed genes, namely: 1, nine human housekeeping genes (from top to bottom: liver glyceraldehyde 3-phosphate dehydrogenase, $\beta$ actin, $\alpha$ tubulin, human major histocompatibility complex (HLA) class I antigen $C-4$ a chain, 23 $k D a$ highly basic protein, ribosomal protein S9, ubiquitin, phospholipase A2,

hypoxanthine-guanine phosphorybosyltransferase); 2, three negative controls (M13 mp18, $\lambda$, and $p U C 18 \mathrm{DNAs}) ; 3$, E2F related transcription factor; 4, caspase $1 ; 5$, caspase $2 ; 6$, caspase 3; 7, caspase 8; 8, caspase 10; 9, tumour necrosis factor (TNF) related apoptosis inducing ligand (TRAIL); 10, nuclear factor AT; 11, inhibitor of caspase activated DNase; 12, Akt1. As expected, the intensity of hybridisation signals was high for positive controls (rectangle 1), whereas the non-human DNA controls (rectangle 2) were negative.

each sample was submitted to conventional histopathological processing and immunophenotyping, the other part was snap frozen in liquid nitrogen and stored at $-80^{\circ} \mathrm{C}$ until use. The presence of lymphoma lesions was checked on frozen sections before storage. For array analysis, samples were divided into two groups. Group 1 comprised nine biopsy specimens that were analysed as total frozen tissues: four samples of B cell follicular lymphoma, two of B cell diffuse large cell lymphoma, and three nonneoplastic lymph nodes with benign reactive lymphadenitis. Group 2 comprised nine cell populations sorted from fresh tissues: malignant
B cells from two patients with follicular lymphoma and two with diffuse large cell lymphoma, reactive $\mathrm{B}$ cells from two benign lymph nodes, reactive $\mathrm{T}$ cells from one benign lymph node, and virgin (mantle zone) B cells and germinal centre $\mathrm{B}$ cells from benign tonsils.

PURIFICATION OF FRESH B CELLS AND RNA PREPARATION

Fresh lymphoma cells were obtained by teasing surgically removed lymph nodes; they were then washed and resuspended in RPMI medium containing $20 \%$ fetal calf serum (FCS). Malignant or reactive $\mathrm{B}$ cells from tissue samples were separated using either magnetic beads conjugated with anti-CD19 monoclonal antibodies (ImmunotechBeckman, Marseille, France), as described previously, ${ }^{7}$ or a standard rosetting technique using 2-aminoethyl-isothiouronium bromide (AET) sensitised sheep red blood cells, as described previously. ${ }^{9}$ The isolated B cell populations, analysed by flow cytometry on a FACScan, were uniformly $>95 \% \mathrm{CD} 20^{+}$and $<5 \% \mathrm{CD}^{+}$; their monoclonality was checked by the exclusive detection of $\kappa$ or $\lambda$ light chains (Dako, Glostrup, Denmark). Fresh virgin B cells and germinal centre B cells were isolated from hyperplastic tonsils as described previously. ${ }^{15}$ The final virgin $\mathrm{B}$ cell population was checked by flow cytometry and was found to be $\mathrm{CD}_{19}{ }^{+}(>98 \%), \mathrm{IgD}^{+}(>98 \%)$, and $\mathrm{CD} 38^{-}$ $(<90 \%)$. The final germinal centre $\mathrm{B}$ cell population was found to be $\mathrm{CD}_{19}{ }^{+}(>98 \%)$, $\mathrm{IgD}^{-}(<2 \%)$, and $\mathrm{CD}^{+} 8^{+}(>90 \%)$. T cells were $>95 \% \mathrm{CD}^{+}$. Sorted cell populations were then either used immediately for the preparation of RNA or cryopreserved. Total RNA was obtained from frozen tissues or sorted cells by lysis in guanidium isothiocyanate and centrifugation over a caesium chloride cushion. RNA integrity was checked by reverse transcriptase PCR (RT-PCR) amplification of the $\beta_{2}$ microglobulin gene. The absence of DNA contamination was verified by PCR amplification of the $\beta_{2}$ microglobulin gene without RT, which gave negative results.

COMPLEX PROBES AND cDNA ARRAYS

Gene expression was analysed using a commercially available nucleic acid array, the ATLAS ${ }^{\mathrm{TM}}$ human apoptosis array (Clontech Laboratories Inc, Palo Alto, California, USA). The membrane contains cDNA fragments representing 217 genes: three non-human genes used as negative controls; nine human housekeeping gene cDNAs used as positive controls and for data normalisation; and 205 cDNAs corresponding to human genes implicated in cell death and cell cycle regulation, including the p53 pathway, the BCL-2 family, the caspase pathway, and cellular ligands/receptors (a list of the genes is available on the following website: http://www.clontech.com). Briefly, each cDNA fragment is $200-600 \mathrm{bp}$ long and has been amplified from a region of the mRNA that lacks the poly(A) tail, repetitive elements, or highly homologous sequences. The amount of each cDNA fragment on the membrane is $10 \mathrm{ng}$, and each clone is spotted in duplicate. 

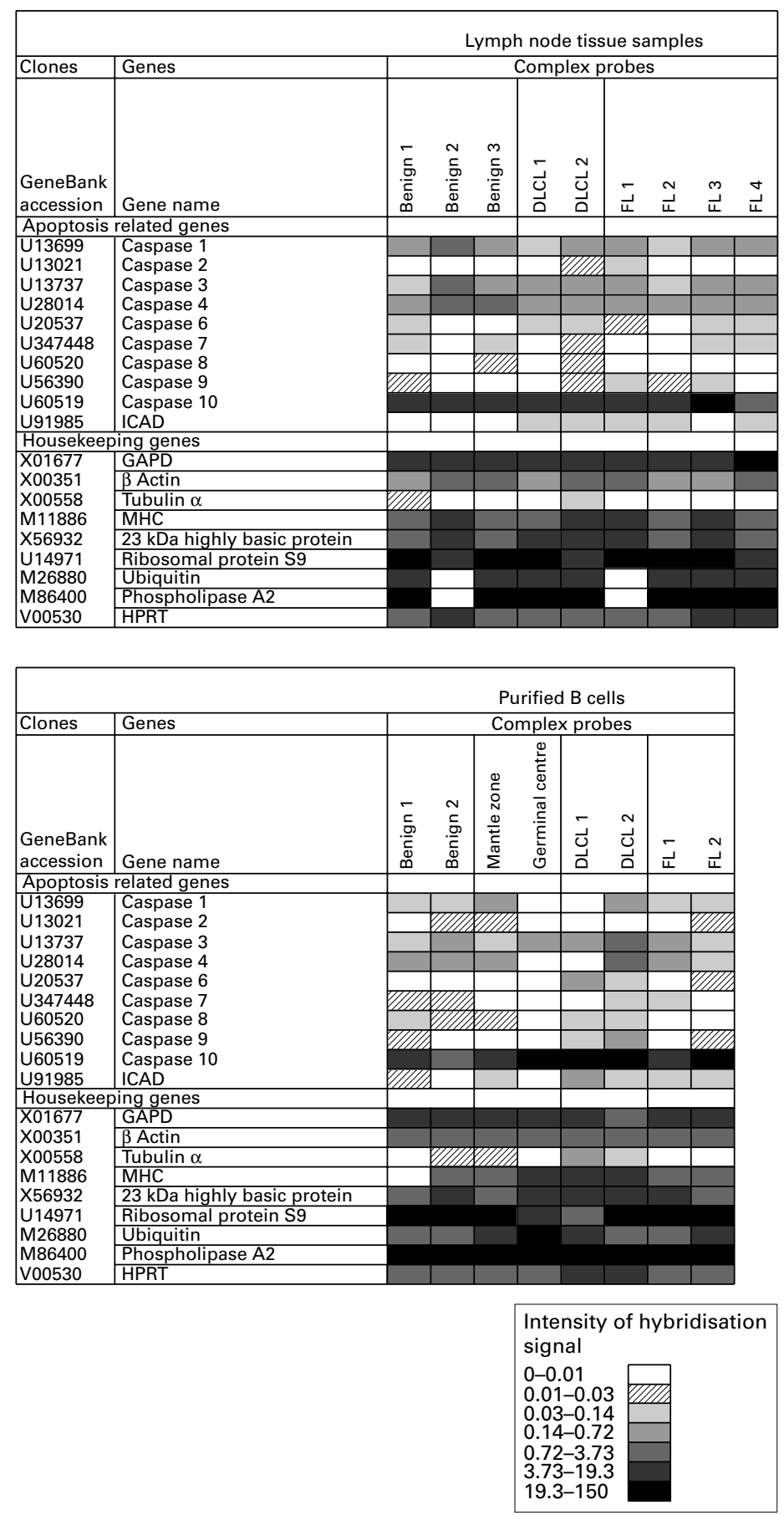

Figure 2 Differential expression profiles of lymph node tissues (nine samples, upper panel) and purified $B$ cells (eight samples, lower panel), restricted to caspases and housekeeping genes. The tissue samples were three non-neoplastic lymph nodes (benign 1 to 3), two B cell diffuse large cell lymphomas (DLCL 1 and 2), and four B cell follicular lymphomas (FL 1 to 4). Sorted cell populations were reactive $B$ cells from two non-neoplastic lymph nodes (benign 1 and 2), virgin B cells, and germinal centre B cells from non-neoplastic tonsil, malignant B cells from two patients with DLCL (DLCL 1 and 2), and from two patients with FL cases (FL 1 and 2). Quantified data were obtained using an imaging plate device. The hybridised membranes were exposed to a FUFIX BAS 1500 system. Data were normalised using the average intensities of seven housekeeping genes as standards. Quantified and normalised hybridisation intensities were represented using a grey colour scale (bottom). As expected from fig 1, the expression of housekeeping genes was globally high, but heterogeneous. DLCL, diffuse large cell lymphoma; FL, follicular lymphoma.

The hybridisation intensity of a particular clone is proportional to the relative abundance of the corresponding mRNA species in the complex probe tested. ${ }^{16}{ }^{17}$

For each cell or tissue sample, $25 \mu \mathrm{g}$ of total RNA and $8 \mu \mathrm{g}$ of oligo(dT) $\left(\mathrm{pd}(\mathrm{T})_{25-30}\right.$; Amer- sham Pharmacia Biotech Europe, Orsay, France) were mixed, heated to $70^{\circ} \mathrm{C}$, and progressively cooled to $42^{\circ} \mathrm{C}$. Complex probes were then prepared by simultaneous reverse transcription and labelling for one hour at $42^{\circ} \mathrm{C}$ in the presence of $50 \mu \mathrm{Ci}$ of $\left[\alpha^{33} \mathrm{P}\right]$-dCTP, $120 \mu \mathrm{M}$ of dCTP, $20 \mathrm{mM}$ each dATP, dTTP, and $\mathrm{dGTP}$, and $200 \mathrm{U}$ of reverse transcriptase (Superscript; Life Technologies, Paisley, UK). After one hour, $200 \mathrm{U}$ of reverse transcriptase were added again, and the mix was incubated at $42^{\circ} \mathrm{C}$, then at $68^{\circ} \mathrm{C}$ for 30 minutes with $1 \mu \mathrm{l}$ of $10 \%$ sodium dodecyl sulphate (SDS), $1 \mu \mathrm{l}$ of $0.5 \mathrm{M}$ EDTA, and $3 \mu \mathrm{l}$ of $3 \mathrm{M} \mathrm{NaOH}$ and equilibrated at room temperature for 15 minutes. Neutralisation was with $10 \mu \mathrm{l}$ of $1 \mathrm{M}$ Tris/ $\mathrm{HCl}$ plus $3 \mu \mathrm{l}$ of $2 \mathrm{~N} \mathrm{HCl}$. Unincorporated nucleotides were removed by filtration on a G50 column. Specific incorporation gave an overall radioactivity of approximately $25 \times 10^{6}$ counts/minute for each probe.

HYBRIDISATION

The probe was denatured for five minutes at $100^{\circ} \mathrm{C}$ with $2 \mu \mathrm{g}$ of polyd(A) $\left(\mathrm{pd}(\mathrm{A})_{80}\right)$, and then incubated in $1 \mathrm{ml}$ of prewarmed hybridisation mix ( $5 \times$ saline sodium citrate (SSC), $5 \times$ Denhart's, $0.5 \%$ SDS, and $500 \mu \mathrm{g}$ sheared salmon testes DNA) for 2.5 hours at $65^{\circ} \mathrm{C}$. The filters were prehybridised for six hours at $68^{\circ} \mathrm{C}$, then hybridised for 48 hours with the probe, washed in SSC/SDS baths, and finally wrapped in plastic and exposed to a Fuji imaging plate. Quantitative data were obtained by scanning in a FUJIX BAS 1500 (Fuji, Clichy, France) system. Hybridisation signatures were determined by a modified version of the BioImage software (Millipore, Molsheim, France).

NORMALISATION AND SIGNAL ANALYSIS

Normalisation is based on the choice of an internal reference that, in independent hybridisations, could correct for differences in labelling, washing, duration of exposure, and progressive degradation of the filter. Normalisation was performed according to the supplier's instructions, by dividing the intensity of signal obtained with each clone by the average intensity of the signals of the seven housekeeping genes that had a relatively constant expression level among the different samples. This procedure was previously shown by the manufacturer to be the most convenient and accurate approach to normalisation (Atlas cDNA Expression Arrays User's Manual; http//www.clontech.com). Our controls showed that it did provide consistency between different hybridisations (see below).

\section{IMMUNOHISTOCHEMISTRY}

To determine the correlation between cDNA array data and IHC, we focused on the expression of the caspases, a family of crucial apoptotic regulators. IHC was performed on paraffin wax sections using specific monoclonal antibodies for caspases $2,3,7,8$, and 9 , after antigen retrieval by heating. Caspase 4 was detected on frozen sections. All antibodies were from Immunotech-Beckman (Marseille, France). All specimens were processed with the 

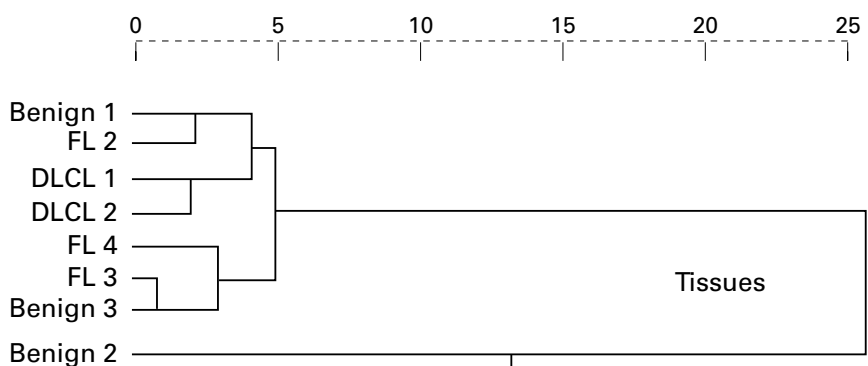

FL 1

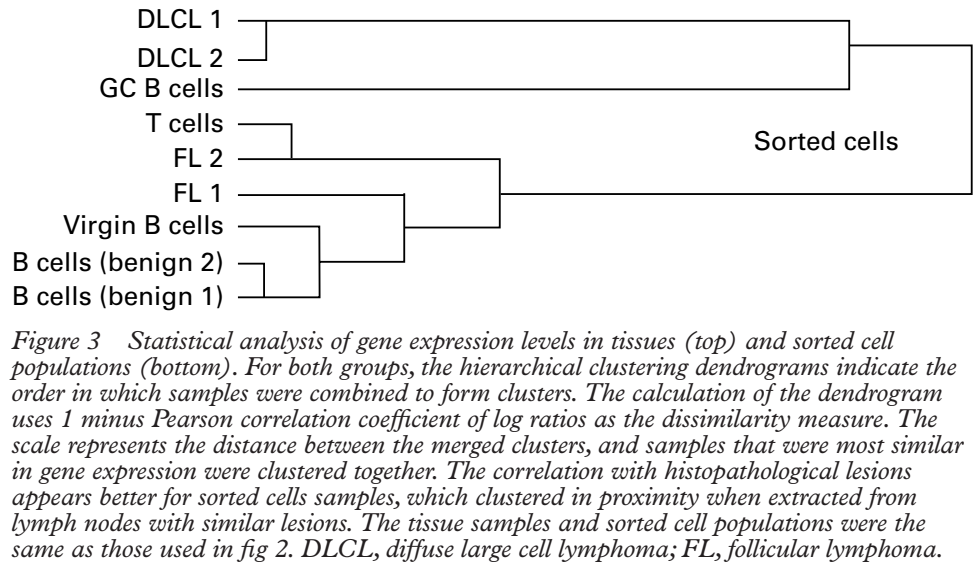

LSAB kit (Dako) according to the supplier's recommendations, counterstained for five minutes in Harris's haematoxylin, and mounted in gelatine. Germinal centre and virgin B cells localised in the mantle zone of reactive lymphoid follicles on sections were compared with sorted cell populations of germinal centre and virgin B cells analysed on arrays.

\section{Results}

CONTROLS

To determine the reproducibility of hybridisations, we first analysed the variation between the duplicate spotted dots in each experiment. For each complex probe, $98 \%$ of the two dots of each clone showed less than a twofold difference in signal intensity, which indicates a relatively homogeneous hybridisation reaction along the membrane surface. The slight variations observed underlines the usefulness of double spotting to increase the accuracy of the data, the resulting measured signal of each clone being the mean of both signals. Secondly, we tested the reproducibility between two independent hybridisation experiments using complex probes made from the same RNA preparation on the same membrane. Mean normalised expression values for each gene were compared in the two experiments. The expression levels of $80 \%$ of the clones showed less than a twofold difference, whereas $90 \%$ of them showed less than a fourfold difference. Finally, we compared the signal intensities for different membranes hybridised with the same probe. After normalisation, $79 \%$ of the clones showed less than a twofold difference in signal intensity, and $90 \%$ of the values deviated less than fivefold. Based on this degree of experimental variation, differences between inde- pendent experiments can be considered reproducible if values in individual gene expression of less than fivefold are not taken into account, which is in accordance with values obtained in other studies. ${ }^{18}$ Most positive controls represented by housekeeping genes showed high degrees of expression, suggesting a good efficiency of array experiments. However, two of the nine housekeeping genes (ubiquitin and phospholipase A2) were excluded from the normalisation procedure because of unexpected variability. Negative control clones gave no signal, indicating the absence of nonspecific hybridisation.

ARRAY PROFILING IN BENIGN AND NEOPLASTIC LYMPHOID SAMPLES

Depending on the samples considered, 35$72 \%$ of cDNAs gave no detectable signal. The intensities of positive signals were highly variable, ranging over three to four orders of magnitude. The results of mRNA quantification are represented in a graphic form, ordered by increasing intensity of shade on a logarithmic scale (fig 2). We applied a hierarchical clustering algorithm using the Pearson correlation coefficient as the measure of similarity and average linkage clustering. As a result, we obtained two dendrograms (trees), one for the group of purified cells and one for the group of tissues, in which similar elements are connected by short branches, and longer branches join elements with diminishing degrees of similarity (fig 3 ). The most notable property of the clustered data was that the purified cells sorted from samples sharing common histological lesions were grouped together, whereas this was not the case for the tissues (fig 3). In the group of sorted cells, the two benign B cell samples were closely related, as were the diffuse large cell lymphoma samples, whereas follicular lymphoma samples were distributed in long terminal branches, suggesting that their gene expression patterns were more heterogeneous. As expected from their low proliferation rates, follicular lymphoma and normal B cells were clustered next to the virgin B cells samples. The expression profiles of diffuse large cell lymphoma samples were largely distinct from those of the follicular lymphoma samples but were close to those of normal germinal centre cells.

A comparison of the gene expression profiles of germinal centre and virgin B cells (fig 1) showed some expected differences because the clones corresponding to transcription factors, such as AP-1, JunB, and NFאB p105, were often expressed at higher levels in germinal

Table 1 Immunohistochemical expression of caspases in hyperplastic follicles from benign lymphoid tissues

\begin{tabular}{lll}
\hline Caspases & Germinal centre cells & Mantle zone cells \\
\hline Caspase 2 & - & +++ \\
Caspase 3 & +++ & - \\
Caspase 4 & + & ++ \\
Caspase 7 & - & - \\
Caspase 8 & + & + \\
Caspase 9 & - & -
\end{tabular}

Intensity of the staining: - , absent; + , weak, ++ , moderate; +++ , strong. 

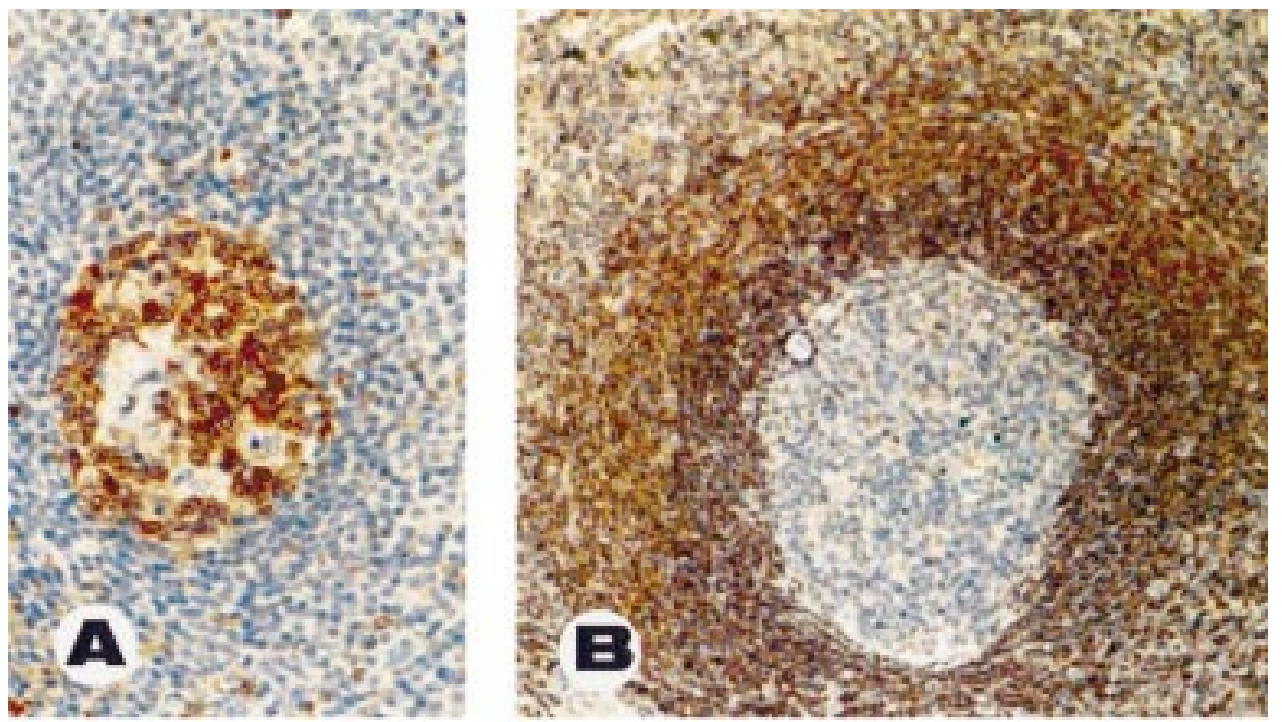

Figure 4
Immunohistochemical (IHC) analysis of caspase expression in reactive follicles and diffuse large $B$ cell lymphoma (DLCL). (A) Caspase 3 expression in germinal centre cells, but not in mantle zone cells. (B) Caspase 2 expression in mantle zone cells but not in germinal centre cells. (C) Caspase 7 expression (bottom left) but not in lymphoid follicles (top right). (D) Caspase 7 expression in lymphoma cells from a patient with diffuse large cell lymphoma: the capsule and residual normal lymphocytes (bottom) are negative. (E) Caspase 9 expression in tonsil epithelial cells (bottom). The positive immunostaining is cytoplasmic and granular, mainly localised to the surface layer. The lymphoid follicles are negative (top). (F) Weak caspase 9 expression in rare diffuse large cell lymphoma cells. These IHC results were correlated with the respective $R N A$ values in each sample, as shown by comparison with fig 2 in the case of the germinal centre and mantle zone cells.
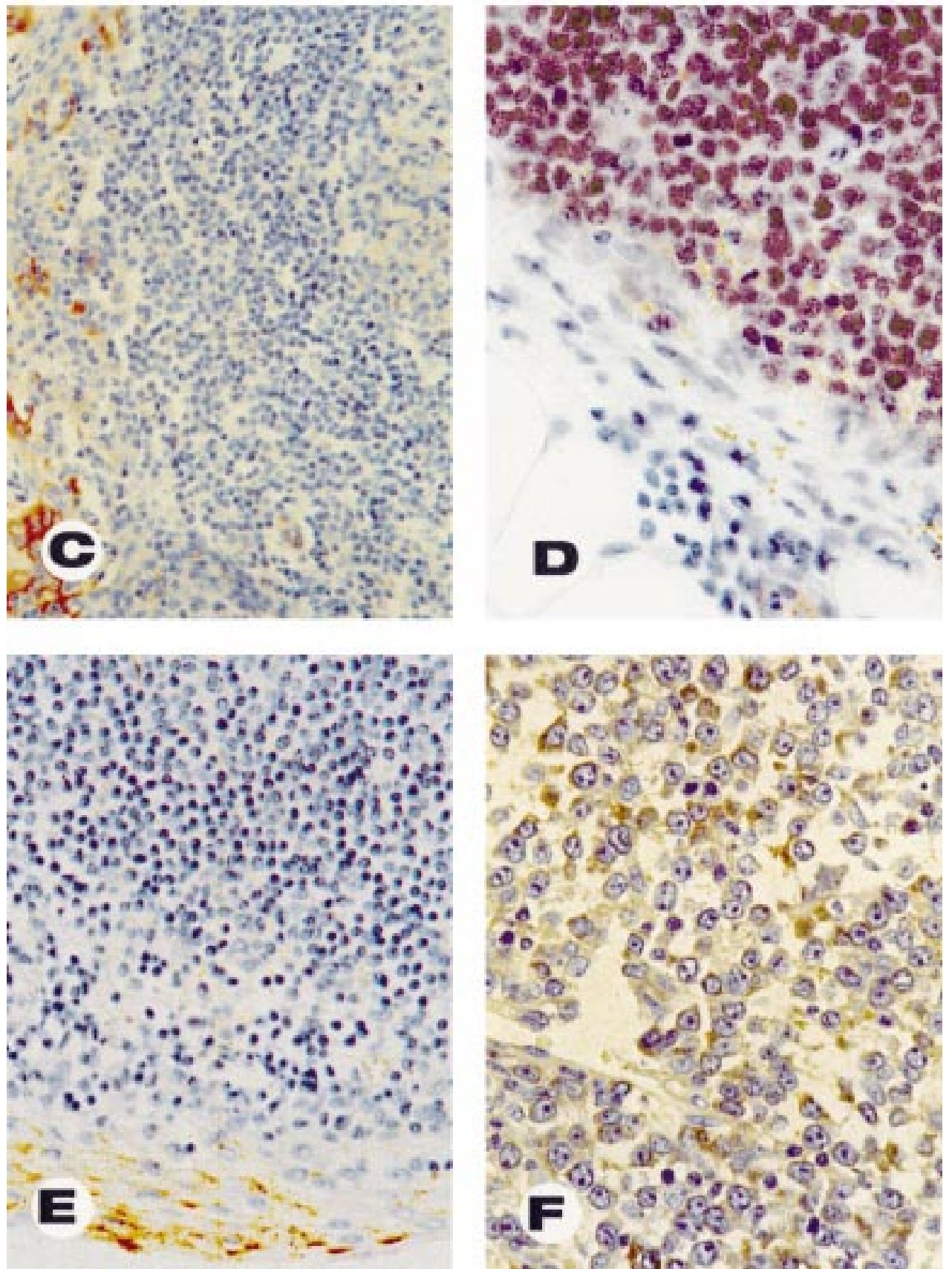
centre cells, whereas BCL-2 expression was higher in virgin B cells, and BAX was lower, as reported previously. ${ }^{19}$

CORRELATION BETWEEN ARRAY PROFILING AND IMMUNODETECTION OF CASPASE EXPRESSION The expression profiles determined by both methods correlated well for most caspases and samples (table 1; fig 2). Caspase 2 expression on arrays was found in both malignant and normal tissues; virgin B cells were weakly positive, whereas germinal centre cells were negative. In array positive samples, IHC showed that caspase 2 was present in lymphoma cells and confirmed that germinal centre cells were negative and mantle zone cells were positive in lymphoid follicles (fig 4).

Caspase 3 array expression levels were globally uniform and moderate in lymphoma tissues, and were higher in germinal centre cells than in virgin B cells and follicular lymphomas (fig 2). These findings were corroborated by IHC (fig 4) as well as previous reports. ${ }^{10}{ }^{11}$

The array expression levels of caspase 4 were moderate and widespread in both nonHodgkin's lymphomas and benign samples; RNA values were higher in virgin B cells than in germinal centre cells. IHC showed that both the mantle zone and germinal centre cell compartments were positive, with a slightly higher staining intensity in mantle zone cells.

Caspase 7 was detected by arrays in five of 10 non-Hodgkin's lymphoma samples and in four of seven benign samples, whereas germinal centre cells and virgin B cells were negative. IHC confirmed the positivity of lymphoma cells in array positive samples, and the negativity of both germinal centre and mantle zone cells from normal follicles (fig 4).

Caspase 8 expression on arrays was globally weak in both non-Hodgkin's lymphomas and benign samples. Expression was higher in virgin $B$ cells than in germinal centre cells. The latter finding was corroborated by IHC, which also showed in non-Hodgkin's lymphomas samples a more widespread expression than expected from the arrays.

Caspase 9 RNA expression was detected in seven of 10 non-Hodgkin's lymphomas and in two of seven benign tissues, whereas germinal centre and virgin B cells were negative. Caspase 9 was localised in rare lymphoma cells by IHC, which confirmed the lack of positivity in germinal centre and mantle zone cells (fig 4).

\section{Discussion}

The possibility of a molecular prognostic classification of non-Hodgkin's lymphomas was recently suggested using a relatively complex array technology. ${ }^{5}$ Our aim was to ask whether another more simple array method could be used as a routine diagnostic tool for haematopathologists. To check the reliability of the array assay, we first focused our attention on germinal centre B cells and virgin B cells, cell populations in which many differences in the expression profiles of apoptosis regulating molecules have been reported previously. ${ }^{1120}$ Some of these expected differences, regarding BCL-2, BAX, caspase 3, transcription factors, and proliferating cell nuclear antigens expression values, were confirmed by the array. These results give an internal consistency to our data and show that comparisons between different samples are reliable for genes with a sufficient degree of expression. In fact, other expected differences regarding genes with low amounts of expression were either not detected or less pronounced. This may reflect the fact that the values for transcripts of low abundance are more subject to background influence during normalisation.

To investigate the correlation between array and IHC data, the pattern of caspase expression was analysed by IHC whenever monoclonal antibodies were available for such experiments. "Effector" caspases such as caspases 3, 6, and 7 are activated by other caspases and located downstream in the cell death pathway. ${ }^{20-22}$ Predominant expression of caspase 3 in germinal centre cells and their malignant counterparts has been described previously. ${ }^{112}$ Although caspases 6 and 7 can replace or potentiate the effects of caspase 3 in some cells and/or apoptosis pathways, ${ }^{21}{ }^{23}$ the weak expression of caspases 6 and 7 seen in normal lymphoid cells and tissues supports the view that caspase 3 is the main effector caspase in normal lymphoid cells.

In addition to its role in apoptosis, caspase 1 was initially described as a factor involved in the processing of interleukin $1 \beta$ (IL-1 $\beta$ ) and the regulation of inflammatory reactions. ${ }^{23}$ In our analysis, caspase 1 was expressed to a high degree in virgin B cells, whereas germinal centre cells were negative, an observation that argues against an apoptotic induction function in B cells. The expression profile of caspase 4 resembled that of caspase 1 . This may be related to the fact that the function of caspase 4 appears to be linked to that of caspase 1 , especially regarding pro-IL-1 $\beta$ processing. ${ }^{23} \mathrm{Al}-$ though caspase 2 acts as a cell death inducer in some circumstances, it may also antagonise apoptosis, as a result of the existence of splice variants. ${ }^{24}{ }^{25}$ Because caspase 2 expression was higher in virgin $B$ cells than in germinal centre cells, caspase 2 may have a predominant survival function in B cells.

"Initiator" caspases, such as caspases 8, 9, and 10 , are activated by a proapoptotic signal such as cell death receptor ligation, and are able to activate effector caspases. ${ }^{26-28}$ Caspase 9 is involved in the mitochondrial pathway of caspase activation. ${ }^{27}$ We did not detect large amounts of caspase 9 in benign lymphoid cells and tissues, which argues against a major role of the mitochondrial pathway in nonneoplastic lesions. Caspase 10 is homologous to caspase $8^{262930}$; a defect in this molecule underlies the resistance of dendritic and lymphoid cells to TRAIL (tumour necrosis factor apoptosis inducing ligand) mediated apoptosis in autoimmune lymphoproliferative syndrome type II. ${ }^{31}$ Our array analysis showed a high, uniform, and predominant expression of caspase 10 when compared with other caspases, thereby suggesting that caspase 10 plays an important role in lymphoid tissues. However, the abundance of caspase 10 mRNA 
might also have non-apoptotic relevance because it was equally present in germinal centre and virgin $\mathrm{B}$ cells.

It is noteworthy that, overall, the immunostaining and RNA expression of the different caspases on arrays correlated well. This suggests that, in the future, pathologists might be able to analyse by IHC potential markers of interest previously identified by array technology. Another important point of our study was to compare array data obtained from purified cell populations and from tissue samples. The reliability of the array analysis on tissues remains questionable, because even non-Hodgkin's lymphoma samples of the same type are intrinsically heterogeneous regarding their neoplastic and reactive cell content. The comparison previously made on three cases of follicular lymphoma only seemed to show a good correlation between the expression profiles of cells and tissues in the same patients. However, our data using the apoptosis array method suggest that the correlation between hierarchical clustering and histopathological features is better for purified cells than for tissues. This point could hamper the use of the method for routine diagnosis purposes because the preparation of sorted cells is technically more complex. However, this point needs to be confirmed on larger series.

The hierarchical clustering of the sorted B cell samples using the apoptosis macroarray of 217 genes was reminiscent of the pattern seen previously using a microarray of 18000 genes. ${ }^{5}$ We provide the additional information that $\mathrm{B}$ cells sorted from benign lymph node samples are segregated from non-Hodgkin's lymphoma samples. This correlation between macroarray profiling and the histopathological pattern of the tissues from which cell samples were sorted suggests that macroarrays of this type may be useful in diagnosis, especially for differentiating between benign and malignant lesions in lymphoid tissues. Additional data are needed to confirm this point.

This work was supported by INSERM, Institut Paoli-Calmettes and a grant from Association pour la Recherche Contre le Cancer. We thank P Haddad from Immunotech-Beckman for the gift of most of the caspases and antibodies.

1 Ramsay R. DNA chips: state of the art. Nat Biotechnol 1998;16:40-4.

2 Rhee $\mathrm{CH}$, Hess $\mathrm{K}$, Jabbur J, et al. cDNA expression array reveals heterogeneous gene expression profiles in three glioblastoma cell lines. Oncogene 1999;18:2711-17.

3 Bertucci F, Van Hulst S, Bernard K, et al. Expression scanning of an array of growth control genes in human tumour cell lines. Oncogene 1999;18:3905-12.

4 Ross DT, Scherf U, Eisen MB, et al. Systemic variation in gene expression patterns in human cancer cell lines. Nat Genet 2000;24:227-34.

5 Alizadeh AA, Eisen MB, Davis RE, et al. Distinct types of large B-cell lymphoma identified by gene expression profiling. Nature 2000;403:503-11.

6 Hermine O, Haioun C, Lepage E, et al. Prognostic significance of bcl-2 protein expression in aggressive non-Hodgkin's lymphoma. Groupe d'Etude des Lymphomes de l'Adulte (GELA). Blood 1996;87:265-74.
7 Xerri L, Devilard E, Parc P, et al. Malignant and reactive cells from human lymphomas frequently express the Fas ligand but display a different sensitivity to Fas-mediated apoptosis. Leukemia 1997;11:1868-77.

8 Xerri L, Devilard E, Bouabdallah R, et al. FADD expression and caspase activation in B-cell lymphomas resistant to Fas-mediated apoptosis. Br f Haematol 1999;106:652-61.

9 Plumas J, Jacob MC, Chaperot L, et al. Tumor B cells from non-Hodgkin's lymphoma are resistant to CD95 (Fas/Apo1)-mediated apoptosis. Blood 1998;91:2875-85.

$10 \mathrm{Li} \mathrm{H}$, Yuan J. Deciphering the pathways of life and death. Curr Opin Cell Biol 1999;11:261-6.

11 Xerri L, Devilard E, Ayello C, et al. Cysteine protease CPP32, but not Ich1-L, is expressed in germinal center B cells and their neoplastic counterparts. Hum Pathol 1997;28:912-21.

12 Krajewski S, Gascoyne R, Zapata J, et al. Immunolocalization of the ICE/ced-3 family protease CPP32 (caspase-3) in non Hodgkin's lymphomas, chronic lymphocytic leukemias and reactive lymph nodes. Blood 1997;89:3817-25.

13 Lee Harris N, Jaffe ES, Stein H, et al. A revised EuropeanAmerican classification of lymphoid neoplasms: a proposal from the international lymphoma study group. Blood 1994; 84:1361-92

14 Lee Harris N, Jaffe ES, Diebold J, et al. WHO classification of neoplastic diseases of the hematopoietic and lymphoid tissues: report of the clinical advisory committee meeting. $\mathcal{F}$ Clin Oncol 1999;17:3835-49.

15 Billian $\mathrm{M}$, Mondière $\mathrm{P}$, Bérard $\mathrm{M}$, et al. Antigen receptor induced apoptosis of human germinal center B-cells is tarinduced apoptosis of human germinal center B-cells is tar14.

16 Zhao N, Hashida H, Takahashi N, et al. High-density cDNA filter analysis: a novel approach for large-scale, quantitative analysis of gene expression. Gene 1995;156:207-13

17 Nguyen C, Rocha D, Granjeaud S, et al. Differential gene expression in the murine thymus assayed by quantitative hybridisation of arrayed cDNA clones. Genomics 1995;29: 207-16.

18 Martin KJ, Kritzman BM, Price LM, et al. Linking gene expression patterns to therapeutic groups in breast cancer. Cancer Res 2000;60:2232-8.

19 Penault-Llorca F, Bouabdallah R, Devilard E, et al. Analysis of Bax expression in human tissues using the anti-Bax 4F11 monoclonal antibody on paraffin sections. Pathol Res Pract 1998;194:457-64.

20 Wolf BB, Schuler M, Echeverri F, et al. Caspase-3 is the primary activator of apoptotic DNA fragmentation via DNA fragmentation factor-45/inhibitor of caspase-activated DNAse inactivation. F Biol Chem 1999;274:30651-6.

21 Germain M, Affar EB, D'Amours D, et al. Cleavage of automodified poly(ADP-ribose) polymerase during apoptosis. 1999;274:28379-84.

22 De Craen MV, Declercq W, Den Brande IV, et al. The proteolytic procaspase activation network: an in vitro analysis. Cell Death Differ 1999;6:1117-24.

23 Los M, Wesselborg S, Schulze-Osthoff K. The role of caspases in development, immunity, and apoptotic signal transduction: lessons from knockout mice. Immunity 1999; 10:629-39.

24 Bergeron L, Perez GI, MacDonald G, et al. Defects in regulation of apoptosis in caspase-2-deficient mice. Genes Dev 1998:12:1304-14.

25 Wang L, Miura M, Bergeron L, et al. Ich-1, an Ice/ced-3related gene, encodes both positive and negative regulators of programmed cell death. Cell 1994;78:739-50.

26 Fernandes-Alnemri T, Armstrong RC, Krebs J, et al. In vitro activation of CPP32 and Mch3 by Mch4, a novel human apoptotic cysteine protease containing two FADD-like domains. Proc Natl Acad Sci U S A 1996;93:7464-9.

27 Muzio M, Chinnaiyan AM, Kischkel FC, et al. FLICE, a novel FADD-homologous ICE/CED-3-like protease, is recruited to the CD95 (Fas/APO-1) death-inducing signaling complex. Cell 1996;85:817-27.

$28 \mathrm{Li}$ P, Nijhawan D, Budihardjo I, et al. Cytochrome C and dATP-dependent formation of Apaf-1/caspase-9 complex nitiates an apoptotic protease cascade. Cell 1997;91:47989

29 Ng PW, Porter AG, Janicke RU. Molecular cloning and characterization of two novel pro-apoptotic isoforms of caspase-10. F Biol Chem 1999;274:10301-8.

30 Vincenz C, Dixit VM. Fas-associated death domain protein interleukin-1beta-converting enzyme 2 (FLICE2), an ICE/ Ced-3 homologue, is proximally involved in CD95-and Ced-3 homologue, is proximally involved in CD95-and 6578-83.

31 Wang J, Zheng L, Lobito A, et al. Inherited human caspase 10 mutations underlie defective lymphocyte and dendritic cell apoptosis in autoimmune lymphoproliferative syndrome type II. Cell 1999;98:47-58. 